\title{
Defects analysis of specialized medical care on the otorhinolaryngology profile in Sverdlovsk oblast at the outpatient and inpatient stage lev- els
}

\author{
Khiiir Abdulkerimov ${ }^{1,2}$, Roman Davydov ${ }^{1,2}$, and Kseniia Kartashova ${ }^{1 *}$ \\ ${ }^{1}$ Ural State Medical University, Faculty of Dentistry, 620028, Yekaterinburg, Russian Federation \\ ${ }^{2}$ Municipal Autonomous Healthcare Institution "City Clinical Hospital No. 40", 620102, Yekaterin- \\ burg, Russian Federation
}

\begin{abstract}
Issues of medical care quality examination are becoming more relevant at present, given the increase in the number of citizens' appeals to the courts, an increase in the flow of patients with complaints to the Ministry of Health, and an analysis of the medical care quality is important for further improving the process of providing citizens with medical care and improving its quality level. The objective of this study was to analyze the structure of citizens' complaints regarding the provision of medical care in the otorhinolaryngology profile, as well as to study the characteristics of quality defects in the provision of medical care.
\end{abstract}

\section{Introduction}

In today's social and economic conditions one of the primary goals of the state social policy of the Russian Federation in health care is guaranteed provision of free medical care of the appropriate quality insured in the CMI system. Appropriate health care quality (HCQ) is the conformity of provided medical care with a modern idea of its required level and scope in this type of pathology, considering generally accepted standards, individual characteristics of the patient, as well as the capabilities of a particular medical institution. A prerequisite and the main mechanism for HCQ evaluation and monitoring in the Russian Federation is the examination carried out at various levels of the health system and regulated by special normative legal acts. [1]

It should be noted that performed examination and treatment results do not always fully satisfy the patient due to the lack of an objective view on the real pathological state latter correction possibilities by means of modern medicine. This indisputable fact is a basis for the emergence and formation of patients' complaints and claims to the MPI providing medical care and explains the subjective component and precariousness of the latter.

Sverdlovsk oblast is the largest region of the Urals and has several features that can also affect the execution of procedures for medical care. Thus, the population of the region according to the Russian Statistics Committee is 4,329,341 people (2018). Population density - 22.28 people per $\mathrm{km}^{2}$ (2018), which is almost triple the average in the Russian Federa-

\footnotetext{
* Corresponding author: kse_sh@mail.ru
} 
tion (8.57). Urban population is $84.63 \%$ (2018), yet there is a significant number of remote and hard-to-reach areas within the region.

The main reasons for the decline in the quality of medical care and subsequent patients' complaints according to international statistics are as follows. The first place is insufficient qualification of medical workers - $24.7 \%$, followed by poor examination of patients $14.7 \%$ and inattentive attitude to patients - 14.1\%. In addition, important factors are treatment process organization $-13.8 \%$, as well as underestimation of patient's condition severity $-2.6 \%$. [1,2]

Analysis of medical records is the most important point in the process of identifying defects in healthcare delivery. The outpatient/inpatient medical chart is a document that must objectively display virtually all actions of medical professionals towards the patient during the stage of his/her stay in polyclinic or in in-patient department. The logging quality of these documents is of serious interest not only from a medical point of view, but also from a point of serious legal importance.

Written citizens' appeals to insurance medical organizations with complaints about the quality of medical care organization are the most massive and affordable way to protect the right to health protection and medical care in the compulsory health insurance system, which is guaranteed in the Russian Federation [2, 3]. At the same time, domestic researchers note a multiple increase in the number of complaints to various supervisory authorities including insurance medical organizations $[3,4,5,6]$. An overwhelming number of appeals is provoked by violation of citizens' rights to be provided with free medical care [6], poor operation arrangement of medical organizations [7], violation of ethics and deontology by medical professionals [7]. According to O.B. Strogonova (2011), the third place among those who have complained to insurance representatives in medical organizations of St. Petersburg is occupied by patients of traumatological and orthopedic profile [6]. Perepechina I.O. et al (2015) note that in Russia on average $46 \%$ of complaints about the quality of medical care are substantiated. Consideration results of citizens' complaints contribute to the creation of a quality management system of medical care [4] and the resolution of conflict situations in pre-trial order [2,3].

The system of patients' rights protection is a set of state and public organizations of extrajudicial examination of appeals by citizens and by judicial bodies making decisions on bills of complaint for damage to life and health compensation while obtaining medical assistance.

Currently, out-of-court consideration of conflicts arising between health institutions (health professionals) and patients includes:

- Analysis of patient complaints to management bodies (administrative procedure);

- Examination of claims made by patients to medical institutions;

- Use of alternative ways to protect patients' rights (negotiation, mediation, arbitration, arbitral tribunal).

Practically, the administrative procedure for resolving an emerging conflict situation is most often applied, which involves a complaint to a superior official or management body on the actions of a particular health professional or medical institution in general that violate the rights of the patient in receiving medical care.

Out of the entire list of possible instances to which citizens can complain about the shortcomings of medical care, the municipal health care authorities are most close to the population. At this level, there is an accumulation of citizens' complaints of this territory, the analysis of which allows to obtain objective information on the quality of medical care provided by subordinate health institutions. 


\subsection{Purpose of the study}

Study of the citizens' appeals structure on medical care issues as well as analysis of defects in medical care quality on the "otorhinolaryngology" profile in the Sverdlovsk region.

\section{Materials and Methods}

In 2017-2019, an expert assessment of the medical care quality of 78 otorhinolaryngological profile patients' treatment cases was carried out, including: 2 - on trials, 18 - with clinical analysis about fatality and 58 - on physical entities' complaints $(\sim 75 \%)$. It should be noted that $42 \%$ of citizens' appeals were complaints made with lawyers' participation.

\section{Results and discussions}

Identified defects in the medical care quality are as follows: defects in the medical documentation availability - 7\% (including no documentation provided, lack of appointments/examinations records), defects in medical documentation registration - $15 \%$ (unreadable handwriting, inserts, hatched areas, torn pages), routing procedures violation - 7\%, insufficiency of administrative resources - 6\% (absence of a profile specialist on site, absence or breakdown of diagnostic equipment). However, gross violations of the medical care quality resulting in deterioration of the patient's health were not detected.

Moreover, based on the texts of appeals there was an attempt made to conditionally identify the possible causes of subjective patients' complaints (Fig. 1).

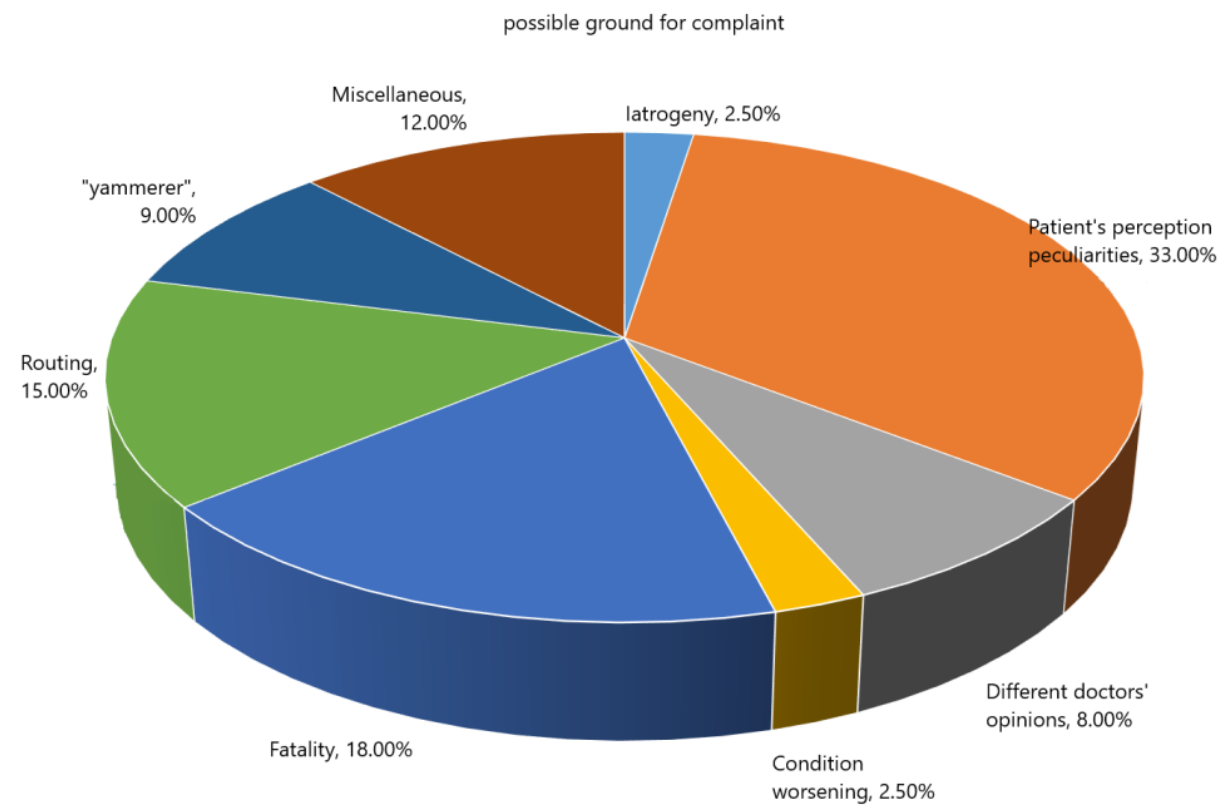

Fig. 1 Structure of possible complaints

In the analysis of possible complaints causes it was noted that a significant part (up to $33 \%$ of cases) is occupied with medical information perception peculiarities of patients or their 
relatives, as well as overstated expectations on otolaryngologic profile disease treatment results. The following can be stated as a typical example: patient's dissatisfaction with recurrence of chronic polyposal rhinosinusitis or lack of hearing recovery in patients suffering from chronic sensorineural hearing loss. This fact is partly an indirect indicator of the doctor's work, namely his/her ability to explain the peculiarities of the disease course, consequences and prognosis to the patient. The second place among the possible reasons for the patients' complaint lodging with $15 \%$ is when the facts of disorderly medical care and routing conducts were revealed. These are the cases in which the patient is given a referral to a non-profile institution or the date of the appointment exceeds the prescribed waiting time, which demonstrates the inconsistency of the medical professionals' actions to the patient. From the patient's point of view, this fact is subjectively perceived as denial of assistance and stimulates the patient to go to various authorities. Another possible reason for complaints should be noted: different (often diametrically opposite) opinions of doctors when patients refer to different medical clinics (including private), which amounted to $8 \%$. Deterioration of patients' condition due to the severity of underlying or associated diseases as well as death accounted for $2.5 \%$ and $18 \%$ respectively and the realized risk of complication developing was $2.5 \%$. Complaints of persons possibly prone to a querulous form of paranoid personality disorder (the so-called "yammerer" - in these cases there are numerous unsubstantiated appeals to various instances: MPI administration, insurance medical companies, RCMIF, Ministry of Health), amounted to $9 \%$. In $12 \%$ of cases, the possible cause of the complaint was not clear.

\section{Conclusions}

1. The structure of complaints and identified defects in the territory of Sverdlovsk oblast has no fundamental differences from such indicators of the all-Russian level, which are available in open sources.

2. Increase of patients' appointment time, equipment improvement, as well as special psychological training of otolaryngologists for explaining the situation, methods and ways of patient's treatment as well as possible outcomes - all of this will result in a decrease in the number of complaints in more than half of cases.

\section{References}

1. A. T. Boyko, S. V. Erofeev, Med. Law, 2 (13), 39-43 (2006)

2. M. A. Sycheva, University bulletin, 1, 242-245 (2015)

3. I. V. Timofeev, Bulletin of Buryat State University, 2, 179- 183 (2014)

4. I. O. Perepechina, D. V. Perepechin, D. V. Smirnova, Research and practice in medicine, 1, 72-75 (2015)

5. O. V. Khodakova, N. F. Shilnikova, N. A. Kuidina, Siberian Medical Journal (Irkutsk), 3, 138-141 (2013)

6. O. B. Stroganova, Human ecology, 2, 23-27 (2011)

7. T. G. Svetlichnaya, O. A. Tsyganova, V. K. Zinkevich, Human Ecology, 2, 50-53 (2010) 